\title{
Encapsulated FeP nanoparticles with in-situ formed P-doped graphene layers: Boosting activity in oxygen reduction reaction
}

\author{
Baoxia $\mathrm{Ni}^{1}$, Rui Chen ${ }^{1}$, Luming $\mathrm{Wu}^{1}$, Pingchuan $\mathrm{Sun}^{2}$ and Tiehong Chen ${ }^{1 *}$
}

\begin{abstract}
Nonprecious metal-based oxygen reduction reaction (ORR) electrocatalysts with high efficiency in both alkaline and acidic media are being intensively studied for the purpose of replacing expensive Pt-based catalysts; however, it is still a challenge to achieve superior ORR performances, especially in acidic media. Herein, by pyrolysis of mixed precursors of diammonium phosphate, melamine and hemin, we prepared a nanocomposite catalyst (denoted as FeP@PGL) composed of nitrogen-doped carbon nanosheets with embedded FeP nanoparticles (NPs), which were encapsulated by in-situ formed phosphorus-doped graphene layers. It is found that phosphorous was preferentially doped in the coating layers on FeP NPs, instead of in the carbon nanosheets. The FeP@PGL catalyst exhibited excellent ORR performance, with the onset and half-wave potential up to 1.01 and $0.90 \mathrm{~V} v s$. the reversible hydrogen electrode (RHE) in alkaline media, and 0.95 and $0.81 \mathrm{~V}$ vs. RHE in acidic media, respectively. By thorough microscopy and spectroscopy characterizations, the interfacial charge transfer between the encapsulated FeP NPs and P-doped graphene layers was identified, and the local work function of the catalyst surface was also reduced by the interfacial interaction. The interfacial synergy between the encapsulated FeP and phosphorus-doped graphene layers was essential to enhance the ORR performance. This study not only demonstrates the promising ORR properties of the encapsulated-FeP-based nanocomposite catalyst, but also provides direct evidence of the interfacial charge transfer effect and its role in ORR process.
\end{abstract}

Keywords: FeP, encapsulation, phosphorus-doped graphene layers, charge transfer, oxygen reduction reaction

\section{INTRODUCTION}

Due to the energy crisis and environmental issues, ecofriendly proton exchange membrane fuel cells (PEMFCs) have attracted great attention because of their high energy density, high efficiency and zero-emission [1,2]. Compared with alkaline membrane fuel cells, PEMFCs are more promising owing to the commercial application of acidic proton exchange membrane. Pt-based catalysts can be used in cathode for oxygen reduction reaction (ORR); however, the high cost and limited reserve hinder the large-scale practical application of Pt-based catalysts in PEMFCs [3-5]. Therefore, developing cost-effective and efficient non-precious metal (NPM) catalysts for ORR, especially in acidic media, is desired.

Among various NPM catalysts, carbon materials are suitable in the acidic media due to their stable corrosion resistance in harsh environment [2,6-9], and in recent years nitrogen-doped carbon catalysts with atomically dispersed iron as active centers $\left(\mathrm{Fe}-\mathrm{N}_{x}\right.$ sites $)$ have emerged as promising candidates in ORR [10-13]. However, the ORR activity of current Fe/N/C catalysts in acidic media is still unsatisfactory in comparison with $\mathrm{Pt} /$ C catalyst, probably due to the difficulty to increase the content of the atomically dispersed iron by high-temperature pyrolysis. Besides the atomically dispersed iron in carbon matrix, iron-based nanoparticles (NPs)/carbon composite catalysts with embedded $\mathrm{Fe}_{3} \mathrm{C}, \mathrm{Fe}_{2} \mathrm{~N}$ or $\mathrm{Fe}_{2} \mathrm{O}_{3}$ NPs, have also been widely studied [14-22]. Due to the species of the NPs, the ORR performances of the catalysts were different. For instance, it was discovered that $\mathrm{Fe} /$ $\mathrm{Fe}_{3} \mathrm{C}$ and $\mathrm{Fe}_{2} \mathrm{~N}$ NPs had positive effect on ORR, while the oxides $\left(\mathrm{Fe}_{2} \mathrm{O}_{3} / \mathrm{Fe}_{3} \mathrm{O}_{4}\right)$ were likely to damage the activity.

\footnotetext{
${ }^{1}$ Institute of New Catalytic Materials Science, School of Materials Science and Engineering, Key Laboratory of Advanced Energy Materials Chemistry (MOE), Nankai University, Tianjin 300350, China

${ }^{2}$ Key Laboratory of Functional Polymer Materials (MOE), College of Chemistry, Nankai University, Tianjin 300071, China

* Corresponding author (email: chenth@nankai.edu.cn)
} 
Although many efficient electrocatalysts of carbon/iron phosphide $(\mathrm{FeP}) \mathrm{NPs}$ were reported for oxygen evolution reaction (OER) and hydrogen evolution reaction (HER), only a few FeP-based ORR catalysts have been studied so far [23-26]. For example, Zhang et al. [24] prepared carbon nanosheets with embedded FeP NPs for OER and ORR. Hu et al. [25] synthesized carbon nanosheets with $\mathrm{Fe}_{x} \mathrm{P}$ NPs whose ORR performance was analyzed in a broad $\mathrm{pH}$ range, and the $E_{1 / 2}$ was $0.653 \mathrm{~V} v s$. the reversible hydrogen electrode (RHE) in acidic media. However, the ORR performance of this kind of FeP-based carbon catalysts is still far from desirable.

The carbon/NPs composite ORR catalysts obtained by pyrolysis would exhibit different compositions, morphologies and structures for the various precursors [27]. Generally, the composite catalysts with NPs supported on carbon matrix can be classified into two categories according to the coating status of the NPs: bare NPs and carbon-encapsulated NPs [14]. During the ORR process, due to the direct contact with the electrolytes, bare NPs would suffer from surface oxidation and dissolution, leading to the decreased and unstable performance. In contrast, carbon-encapsulated NPs would benefit from the protection of the coating [28-30]. Furthermore, the synergy between the NPs and the coating would give rise to the enhanced ORR performance, and as calculated by density function theory, the charge transfer between the encapsulated NPs and the coating layers would be beneficial to the ORR [20,31]. For the fabrication of carbon/NPs composite catalysts, the carbon matrix support was generally formed by pyrolysis of the precursors, and the carbonization process of the coating layer on NPs could be catalyzed by the surface of NPs depending on the species of the NPs. Due to different formation mechanisms, the structure and composition of the carbon matrix and the coating layers on NPs would be different and play different roles in ORR; however, this issue has been neglected, and the composition difference between the carbon matrix and the carbon coating of NPs has never been studied in previous studies on carbon/NPs composite ORR catalysts.

Herein, a nanocomposite catalyst (denoted as FeP@PGL) was fabricated by pyrolysis of mixed precursor of diammonium phosphate, melamine and hemin. The catalyst was composed of nitrogen-doped carbon nanosheets with embedded FeP NPs, which were encapsulated by in-situ formed phosphorus-doped graphene layers. The FeP@PGL catalyst exhibited excellent ORR performance, with positive onset and half-wave potentials up to 1.01 and $0.90 \mathrm{~V} v s$. RHE in alkaline media, and 0.95 and $0.81 \mathrm{~V}$ vs. RHE in acidic media, respectively. The interfacial charge transfer between encapsulated FeP NPs and the coating phosphorus-doped graphene layers was identified, and the local work function of the catalyst surface was also reduced by the interfacial interaction. The interfacial charge behavior between the encapsulated $\mathrm{FeP}$ and $\mathrm{P}$-doped graphene layers played a vital role in enhancing the ORR performance.

\section{EXPERIMENTAL SECTION}

\section{Catalysts preparation}

Synthesis of FeP@PGL: Typically, diammonium phosphate $(3.0 \mathrm{~g})$ was added into $20 \mathrm{~mL}$ of ethanol and distilled water (1:1) mixture solution. Then melamine ( $4.0 \mathrm{~g})$ and hemin $(0.40 \mathrm{~g})$ were added to the above solution sequentially. After thorough stirring, the mixed solution was dried until the solution completely evaporated. The dried precursor composite was ground and placed into crucibles, and then pyrolyzed at $1000^{\circ} \mathrm{C}$ in $\mathrm{N}_{2}$ atmosphere for $2 \mathrm{~h}$. To remove unstable phases, the pyrolyzed sample was treated in $1 \mathrm{~mol} \mathrm{~L}^{-1} \mathrm{HCl}$ solution at $90^{\circ} \mathrm{C}$ for $12 \mathrm{~h}$, and then washed with distilled water until it was neutral and dried to obtain the final sample denoted as FeP@PGL. Other samples prepared by the same procedure except for the hemin dosage and annealing temperature, were denoted as FeP@PGL-X-T (X is the dosage of hemin, and $\mathrm{T}$ is the annealing temperature).

Synthesis of PNC: The synthesis procedure is similar to that of FeP@PGL but in the absence of hemin, and the obtained sample was denoted as PNC.

Synthesis of bare FeP and FeP/PNC-mix: The synthesis procedure is similar to that of FeP@PGL in the absence of melamine, and the obtained sample was denoted as bare FeP. FeP/PNC-mix was the physical mixture of about $0.12 \mathrm{~g}$ of PNC and $0.10 \mathrm{~g}$ of bare FeP.

Synthesis of FeP@PGL-BM: FeP@PGL was ground by ball-milling at $1400 \mathrm{rpm}$ for $2 \mathrm{~h}$, and leached in $1 \mathrm{~mol} \mathrm{~L}^{-1}$ $\mathrm{HCl}$ solution at $90^{\circ} \mathrm{C}$ for $24 \mathrm{~h}$ to remove FeP NPs. The final sample was named FeP@PGL-BM.

\section{Characterizations}

Field-emission scanning electron microscopy (FESEM; JEOL, JSM-7800F, $15 \mathrm{kV}$ ) was used to analyze the surface morphology of catalysts. Transmission electron microscopy (TEM) measurements were performed on a JEM2800 microscope, working at $200 \mathrm{kV}$. The scanning transmission electron microscopy (STEM) image and electron energy loss spectroscopy (EELS) were acquired on a Philips Tecnai F20 microscope, working at $200 \mathrm{kV}$. 
Samples were ultrasonically dispersed in ethanol solution and dropped onto copper grids to conduct TEM measurements. The powder X-ray diffraction (XRD) patterns of samples were obtained from a Rigaku Smart Lab $3 \mathrm{~kW}$ powder diffractometer using $\mathrm{Cu} \mathrm{Ka}$ radiation. X-ray photoelectron spectroscopy (XPS, Thermo Scientific ESCALAB 250Xi spectrometer) was applied to measure the surface information of samples. UV photoelectron spectroscopy (UPS) measurements were carried out at room temperature using $21.22 \mathrm{eV}$ He Ia source. The Fermi level position was calibrated using gold as a reference. The local work functions of samples were derived from UPS spectra using the equation $\Phi=h v-\left(E_{\text {Cutoff }}-E_{\text {Fermi }}\right)$ [32]. Nitrogen adsorption and desorption isotherms were measured on a BELSORP-mini II sorption analyzer at $77 \mathrm{~K}$. The surface area was calculated by the BrunauerEmmett-Teller (BET) equation using the linear part $(0.05$ $\left.<P / P_{0}<0.25\right)$ of the adsorption isotherm.

\section{Electrochemical measurements}

An RRDE-3A (ALS, Japan) device in conjunction with a CHI660D electrochemical workstation $(\mathrm{CH}$ instrument Co. USA) was utilized to test the ORR performance of samples via a three-electrode system including a glassy carbon rotating disk electrode (RDE) coated with catalysts, a carbon rod counter electrode and a $\mathrm{Ag} / \mathrm{AgCl}$ reference electrode. The working electrode was produced as follows: firstly, the catalyst was dispersed in a mixed solution $\left(800 \mu \mathrm{L}\right.$ of $\mathrm{H}_{2} \mathrm{O}, 180 \mu \mathrm{L}$ of isopropanol and $20 \mu \mathrm{L}$ of $5 \mathrm{wt} \%$ Nafion solution). After sonication for at least $30 \mathrm{~min}$, the catalyst ink was dropped onto the RDE surface $(5 \mathrm{~mm}$ inner diameter) which was freshly polished before use. Then the RDE was air-dried to allow solvent evaporation at room temperature. The mass loading of the prepared catalysts on the work electrode was 300 and $600 \mu \mathrm{g} \mathrm{cm}^{-2}$ in alkaline and acidic media, respectively. The mass loading of the commercial $\mathrm{Pt} / \mathrm{C}$ catalyst $(20 \mathrm{wt} \% \mathrm{Pt})$ was $150 \mu \mathrm{g} \mathrm{cm}^{-2}$ in both alkaline and acidic media. Before tests, the electrolytes were saturated with oxygen gas, and the linear sweep voltammetry (LSV) curves were recorded at a scan rate of $5 \mathrm{mV} \mathrm{s}^{-1}$. All potentials were converted to the RHE using the Nernst equation $E_{(\mathrm{RHE})}=E_{(\mathrm{Ag} / \mathrm{AgCl})}+0.0592 \mathrm{pH}+0.205$. The chronoamperometric measurement $(i-t)$ was performed at $0.5 \mathrm{~V}$ vs. RHE in $\mathrm{O}_{2}$-saturated $0.5 \mathrm{~mol} \mathrm{~L}^{-1} \mathrm{H}_{2} \mathrm{SO}_{4}$ or $0.1 \mathrm{~mol} \mathrm{~L}^{-1} \mathrm{KOH}$. The tolerance of catalysts to methanol was tested by adding $2 \mathrm{~mL}$ methanol into $\mathrm{O}_{2}$-saturated electrolytes. Electrochemical impedance spectroscopy (EIS) measurements were performed in the frequency range of $0.01-10^{5} \mathrm{~Hz}$ with an amplitude of $5 \mathrm{mV}$.

\section{Primary Zn-air battery test}

A homemade $\mathrm{Zn}$-air battery was fabricated with a $\mathrm{Zn}$ foil as the anode and the catalyst loaded on the carbon paper with gas diffusion layer as the cathode (catalyst loading of $1.0 \mathrm{mg} \mathrm{cm}^{-2}$ ), and the electrolyte was $6 \mathrm{~mol} \mathrm{~L}^{-1} \mathrm{KOH}$ and $0.2 \mathrm{~mol} \mathrm{~L}^{-1} \mathrm{Zn}(\mathrm{Ac})_{2}$ solution. The experiment was carried out with a CHI660D electrochemical workstation and galvanostatic discharge curves were performed on the LAND testing system.

\section{RESULTS AND DISCUSSION}

\section{Morphology and structure characterization}

For the synthesis of FeP@PGL, the precursor mixture of diammonium phosphate, melamine and hemin were directly pyrolyzed under $\mathrm{N}_{2}$ atmosphere. In the XRD pattern of FeP@PGL (Fig. 1a), two broad peaks at $2 \theta \sim 25^{\circ}$ and $44^{\circ}$ are assigned to (002) and (101) planes of graphitic carbon, respectively [33], and the other sharp peaks are assigned to FeP (JSPDS 71-2262). The sample contained micropores and mesopores with the specific surface area of $580 \mathrm{~m}^{2} \mathrm{~g}^{-1}$, as characterized by nitrogen adsorption (Fig. $1 \mathrm{~b}$ and Table S1). The porous structure is beneficial to mass transfer and active site exposure, thus promoting the oxygen reduction process [34,35]. From the SEM images in Fig. 2a, b, FeP@PGL exhibits the morphology of nanosheets with abundant embedded NPs, which are FeP NPs according to the XRD pattern. The average size of the FeP NPs is around $30 \mathrm{~nm}$ as observed in TEM images (Fig. 2c, d), and they are well dispersed on the carbon nanosheet matrix, like dewdrops on a leaf. It is noteworthy that each FeP particle is coated with thin carbon layers (Fig. 2e), and the HRTEM images (Fig. 2f and Fig. S1) clearly show that the FeP NPs are encapsulated by 3-5 layers of graphene-like carbon. The lattice fringes with interplanar distance of well crystallized NPs is about $0.188 \mathrm{~nm}$, in accord with the (211) lattice plane of FeP. The STEM-bright field (BF) image and the corresponding elemental mapping images of FeP@PGL (Fig. $2 \mathrm{~g}-\mathrm{k}$ ) show that $\mathrm{C}$ and $\mathrm{N}$ are homogeneously dispersed in the carbon nanosheet matrix, while $\mathrm{Fe}$ and $\mathrm{P}$ signals originate from the encapsulated FeP NPs. In Fig. 1a, FeP diffraction peaks of FeP@PGL correspond exactly to the $\mathrm{FeP}$ standard card without deviation, implying that nitrogen was not incorporated into the FeP crystalline NPs.

Based on the above results, the FeP@PGL was a nanocomposite catalyst composed of $\mathrm{N}$-doped carbon matrix with embedded $\mathrm{FeP}$ NPs encapsulated within graphene layers. As shown in the TEM images, the gra- 

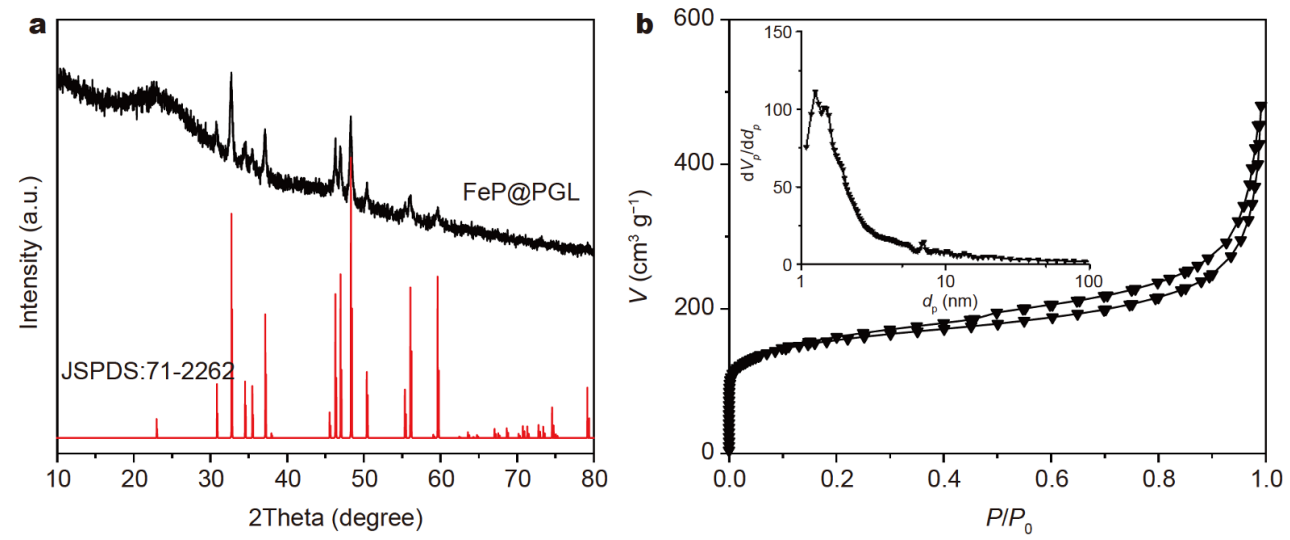

Figure 1 (a) The XRD pattern of FeP@PGL. (b) The nitrogen adsorption-desorption isotherm of FeP@PGL, and (inset) the corresponding pore size distribution curve.

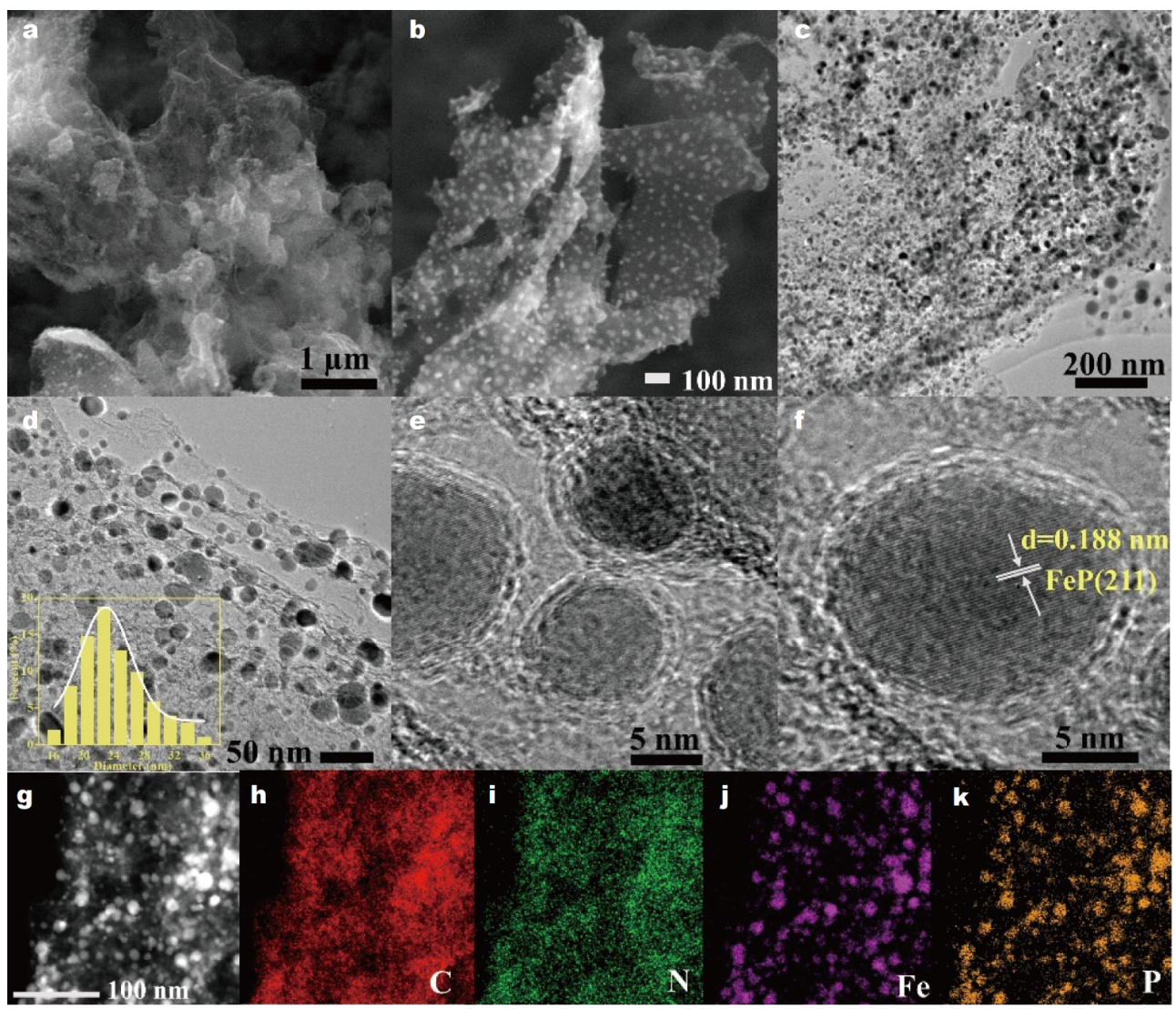

Figure 2 (a, b) SEM, (c, d) TEM, (e, f) HRTEM of FeP@PGL; (g-k) STEM-BF image of FeP@PGL and the corresponding mapping images of C, N, Fe and $\mathrm{P}$.

phitization degree of the carbon layer coating on FeP was obviously higher than that of the carbon nanosheet matrix, probably due to the catalytic graphitization effect of $\mathrm{FeP}$ during the pyrolysis process. This implies that the formation mechanism of the carbon matrix and the graphene layers could be different, and the composition of the two carbon species would not be identical. Due to its high spatial resolution, EELS was applied to identify the compositions of the two categories of carbon species, i.e., the carbon nanosheets and the coating layers on FeP 
NPs. As shown in Fig. 3a, the EELS line scan was performed across a single carbon-coated FeP NP. From the profiles of $\mathrm{Fe}$ and $\mathrm{P}$ elements (Fig. 3b), the P profile did not coincide with that of $\mathrm{Fe}$ on both sides of the nanoparticle, indicating that the phosphorus signal originated not only from the FeP NPs, but also from the coating graphene layers. The distance between the profiles of $\mathrm{Fe}$ and $\mathrm{P}$ on both sides was about $1.2 \mathrm{~nm}$, just corresponding to the 3-5 graphene layers as observed in TEM images. The difference of apparent intensities of the $\mathrm{Fe}$ and $\mathrm{P}$ line scan profiles was due to different scattering cross-section of $\mathrm{Fe}$ and $\mathrm{P}$ atoms. The EELS spectra collected at the regions of $\mathrm{A}$ (carbon matrix) and $\mathrm{B}$ (coating graphene layers) are shown in Fig. 3c, d, respectively, and there is almost no signal of $\mathrm{P}$ L-edge on carbon matrix, while an obvious signal at $(130 \pm 0.5) \mathrm{eV}$ was observed on the coating graphene layers, clearly indicating P-doping in the graphene layers. The absence of Fe L-edge signal as shown in Fig. 3d indicates that the P L-edge signal observed on the coating carbon layers was not due to the inclusion of the signal from FeP NPs.

XPS was utilized to obtain the overall surface composition of FeP@PGL, and the wide survey scan shows the existence of $\mathrm{C}, \mathrm{N}, \mathrm{P}, \mathrm{Fe}$, and $\mathrm{O}$ elements (Fig. 4a). The P 2p spectrum of FeP@PGL is shown in Fig. 4b, and the peaks at 129.5 and $130.4 \mathrm{eV}$ are assigned to $\mathrm{P} 2 \mathrm{p}_{3 / 2}$ and $\mathrm{P} 2 \mathrm{p}_{1 / 2}$ in $\mathrm{FeP}$, respectively. There is a tiny signal at $134.6 \mathrm{eV}$ which could be ascribed to $\mathrm{P}-\mathrm{O}$ bonding. The other signal at $132.6 \mathrm{eV}$ is assigned to phosphorus bonded to carbon (denoted as $\mathrm{P}-\mathrm{C}$ ) $[36,37]$, and the content of $\mathrm{P}-$ $\mathrm{C}$ is about 1.1 at $\%$ by XPS (Table S2). As the space resolution of XPS was relatively low, the 1.1 at\% of P-C represented the total phosphorus content contributed from both carbon matrix and graphene layers on $\mathrm{FeP}$ (not including the contribution of FeP NPs, as the phosphorus signals of $\mathrm{P}-\mathrm{C}$ and FeP are well separated in the $\mathrm{P} 2 \mathrm{p}$ XPS spectrum). The STEM-BF image of FeP@PGL at the site of carbon matrix (in absence of encapsulated FeP NPs) is shown in Fig. S2a, and the corresponding energy dispersive spectroscopy (EDS) analysis provides the element contents as summarized in the inset of Fig. S2b with nitrogen content of 2.1 at $\%$, negligible $\mathrm{Fe}$ content of 0.03 at $\%$ and $\mathrm{P}$ content of 0.2 at $\%$, indicating that the carbon nanosheet matrix is composed of $\mathrm{N}$-doped carbon, with only traces of Fe and P. Therefore, the phosphorus content corresponding to the $\mathrm{P}-\mathrm{C}$ peak in XPS
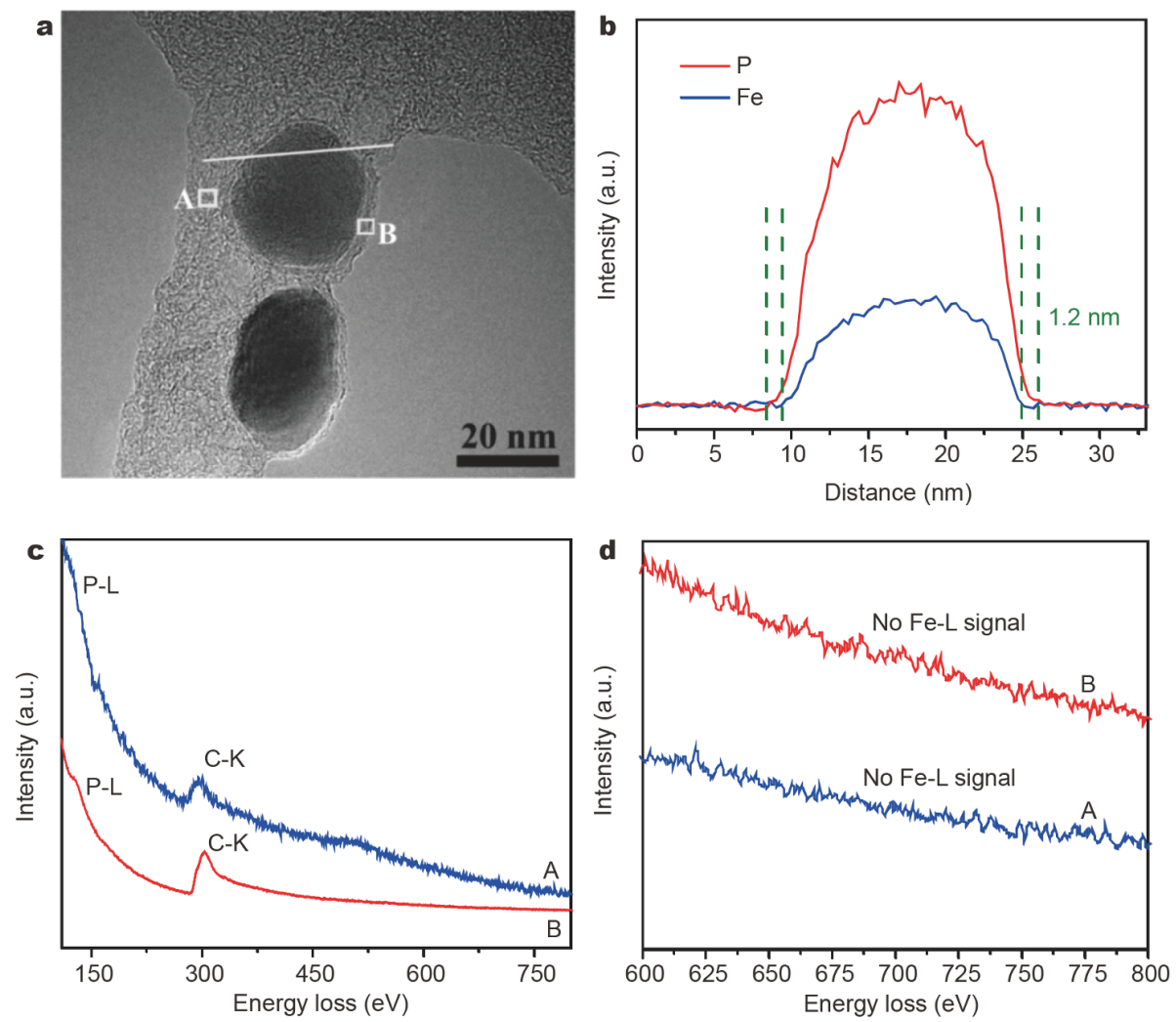

Figure 3 (a) STEM image of FeP@PGL, (b) EELS elemental line profiles of Fe (blue) and P (red) of a single encapsulated FeP NPs, (c, d) EELS spectra of $\mathrm{P}$ and $\mathrm{Fe}$ at the carbon matrix (A) or the carbon layers (B), respectively. 

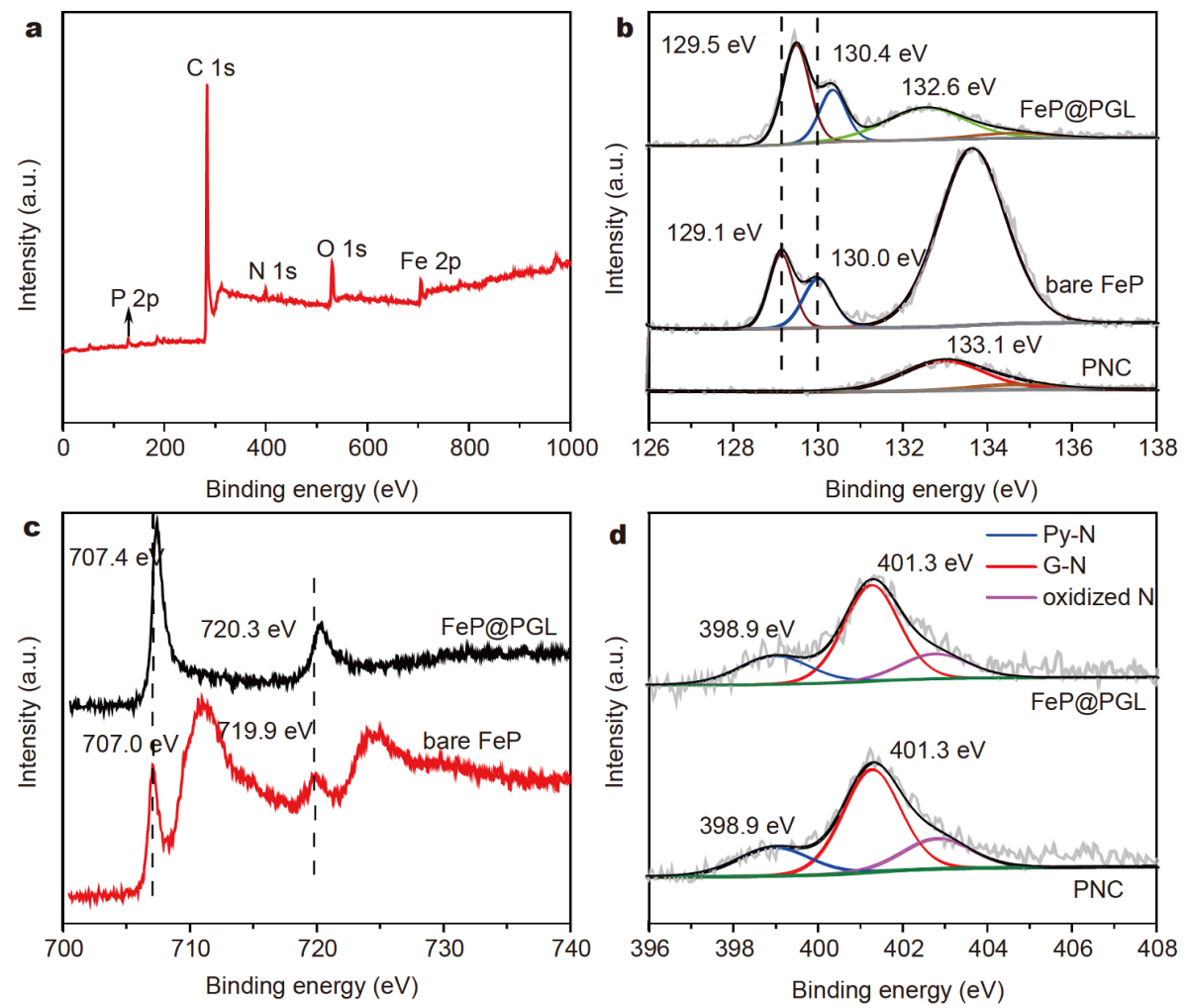

Figure 4 (a) The wide XPS survey of FeP@PGL. (b) The P 2p XPS spectra of FeP@PGL, bare FeP and PNC. (c) The Fe 2p XPS spectra of FeP@PGL and bare FeP. (d) The N 1s XPS spectra of FeP@PGL and PNC.

mainly originated from the doping phosphorus in the graphene layers, in consistence with the results of EELS. During the pyrolysis process, $\mathrm{FeP}$ nanocrystals would be preferentially formed by annealing of Fe-containing and P-containing precursors. The graphene layers on FeP could be generated in the carbonization process catalyzed by FeP NPs, while the carbon nanosheet matrix was derived from the pyrolysis of the carbon and nitrogen sources. Thus it would be reasonable that phosphorus was preferentially doped in the coating layers on FeP NPs.

As shown in the Fe 2p XPS spectrum (Fig. 4c), two sharp peaks at 707.4 and $720.3 \mathrm{eV}$ are ascribed to $\mathrm{Fe} 2 \mathrm{p}_{3 / 2}$ and $\mathrm{Fe} 2 \mathrm{p}_{1 / 2}$ in FeP, respectively [36,38]. The $\mathrm{N} 1 \mathrm{~s}$ spectrum could be deconvoluted into three peaks at 398.9, 401.3 and $402.8 \mathrm{eV}$ as shown in Fig. $4 \mathrm{~d}$, corresponding to pyridinic-N (Py-N), graphitic-N (G-N) and oxidized-N, respectively [39]. Nitrogen doping in FeP@PGL is as low as 2.2 at $\%$, in which graphitic- $\mathrm{N}$ accounted for $74 \%$ and pyridinic-N accounted for only $15 \%$. The content of Py-N is about 0.3 at $\%$ of the total element content (Table S2), and it is a negligible share. As was reported in $\mathrm{Fe} / \mathrm{N} / \mathrm{C}$ catalysts [40-42], Py- $\mathrm{N}$ species are necessary to construct the $\mathrm{Fe}-\mathrm{N}_{x}$ active sites, and it could be deduced that for
FeP@PGL, the Fe inclusion is mainly in the form of FeP NPs, and there is a negligible share of $\mathrm{Fe}-\mathrm{N}_{x}$ sites due to the trace of $\mathrm{Py}-\mathrm{N}$ in the carbon sheet matrix. Based on the above results, it could be concluded that the FeP@PGL nanocomposite held abundant FeP NPs, embedded in the $\mathrm{N}$-doped carbon nanosheets matrix, and encapsulated by P-doped graphene layers.

As a control experiment, the precursor mixture of diammonium phosphate and melamine (without hemin) was pyrolyzed via the same procedure of FeP@PGL and the control sample was denoted as PNC. The XRD pattern (Fig. S3) of PNC indicates its nature of graphitic carbon and the SEM image (Fig. S4) shows its porous structure. The wide XPS survey confirms that it is composed of $\mathrm{C}, \mathrm{N}, \mathrm{P}$ and $\mathrm{O}$ (Fig. S5). Three peaks in $\mathrm{N} 1 \mathrm{~s}$ spectrum of PNC are in good agreement with those of FeP@PGL (Fig. 4d), implying the similar bonding situation of $\mathrm{N}$ doping. These results imply again nitrogen in FeP@PGL is not incorporated into FeP NPs, consistent with the XRD results (Fig. 1a). A broad peak of P 2p spectrum at $133.1 \mathrm{eV}$ is assigned to $\mathrm{P}-\mathrm{C}$ bonding in $\mathrm{P}$ doped carbon matrix, and a tiny peak is assigned to $\mathrm{P}-\mathrm{O}$ bonding (Fig. 4b) [39]. For PNC, without hemin as Fe 
source, phosphorus and nitrogen were uniformly doped in carbon matrix instead of the formation of FeP NPs.

Another control experiment was conducted with the precursors of diammonium phosphate and hemin but without melamine via the same procedure for FeP@PGL, and the obtained sample was bare FeP particles, as characterized by XRD and SEM (Figs S6, S7). The P 2p XPS spectrum of the bare FeP is deconvoluted into three peaks (Fig. 4b), and the peaks at 129.1 and $130.0 \mathrm{eV}$ are assigned to $\mathrm{P} 2 \mathrm{p}_{3 / 2}$ and $\mathrm{P} 2 \mathrm{p}_{1 / 2}$ of $\mathrm{FeP}$, and the other strong one at $133.7 \mathrm{eV}$ is assigned to the surface oxidized FeP species, due to unavoidable surface oxidation of bare FeP when exposed to air $[38,43,44]$. In Fe 2p XPS spectrum of bare FeP (Fig. 4c), the peaks at 707.0 and $719.9 \mathrm{eV}$ are assigned to $\mathrm{Fe} 2 \mathrm{p}_{3 / 2}$ and $\mathrm{Fe} 2 \mathrm{p}_{1 / 2}$ of $\mathrm{FeP}$, respectively, and the two broad peaks at 711.1 and $724.6 \mathrm{eV}$ are ascribed to the surface oxidized FeP species $[35,38,43]$. For comparison, both the $\mathrm{P} 2 \mathrm{p}$ and Fe $2 \mathrm{p}$ signals corresponding to the surface oxidized $\mathrm{FeP}$ are absent in the XPS spectrum of FeP@PGL, due to the surface protection from oxidation by the coating graphene layers. It should be noted that both the P $2 \mathrm{p}$ and Fe 2p peaks of FeP in FeP@PGL exhibit $0.4 \mathrm{eV}$ positive shift compared with those of bare FeP (Fig. 4b, c), and this could be explained by electron transfer from FeP NPs to their coating carbon layers in FeP@PGL, resulting in the increased binding energy of Fe and $\mathrm{P}$ in encapsulated FeP NPs.

\section{ORR activities of catalysts in acidic and alkaline media}

Besides FeP@PGL, a series of samples were also prepared either under different pyrolysis temperature or with different hemin dosages (Figs S8, S9), and all samples were tested in ORR. The ORR performance of FeP@PGL-X-T was assessed by LSV with the RDE measurement in $\mathrm{O}_{2^{-}}$ saturated acidic media $\left(0.5 \mathrm{~mol} \mathrm{~L}^{-1} \mathrm{H}_{2} \mathrm{SO}_{4}\right)$ and alkaline media $\left(0.1 \mathrm{~mol} \mathrm{~L}^{-1} \mathrm{KOH}\right)$, respectively. The pyrolysis temperature is an important factor to affect structures and compositions of products [45], and the optimum pyrolysis temperature appeared at $1000^{\circ} \mathrm{C}$ by comparing LSV curves (Fig. S10). The dosage of hemin is another factor to modulate the ORR activities of catalysts (shown in Fig. 5), and there is an optimal value of hemin in synthesis (corresponding to the sample FeP@PGL). Regulating the dosage of hemin in precursors could obtain samples with different sizes of FeP NPs (Fig. S11). When the dosage was low, the size of the NPs was relatively small and uniform. With the increase of the hemin dosage, more amount of FeP NPs were formed; however, the size of the NPs increased and became non-uniform. The ORR performance of the samples prepared with 0.1 to $0.4 \mathrm{~g}$ hemin (Fig. 5) gradually improved with the increase of hemin dosage, but when the dosage was $0.5 \mathrm{~g}$, the performance degraded. With increasing dosage of hemin in precursors, the NPs quantity in the obtained catalysts increased and the size also increased. The increased amount of FeP could enlarge the interfacial area between the FeP and the coating P-doped carbon layers; however, the increase of size could reduce the interfacial area. Therefore, there was an optimized dosage of hemin during the synthesis. Moreover, charge transfer resistance $\left(R_{\mathrm{ct}}\right)$ is another important factor which affects the electrocatalytic performance of catalysts. EIS was performed to analyze the charge transfer capacity of the catalysts. The Nyquist plot (Fig. S12) shows that the fitted $R_{\mathrm{ct}}$ of FeP@PGL is smaller than the others, indicating faster charge transfer and more favorable reaction kinetics of FeP@PGL.

As shown in Fig. 6a, FeP@PGL exhibits highly efficient ORR catalytic activity in $0.5 \mathrm{~mol} \mathrm{~L}^{-1} \mathrm{H}_{2} \mathrm{SO}_{4}$, and the onset
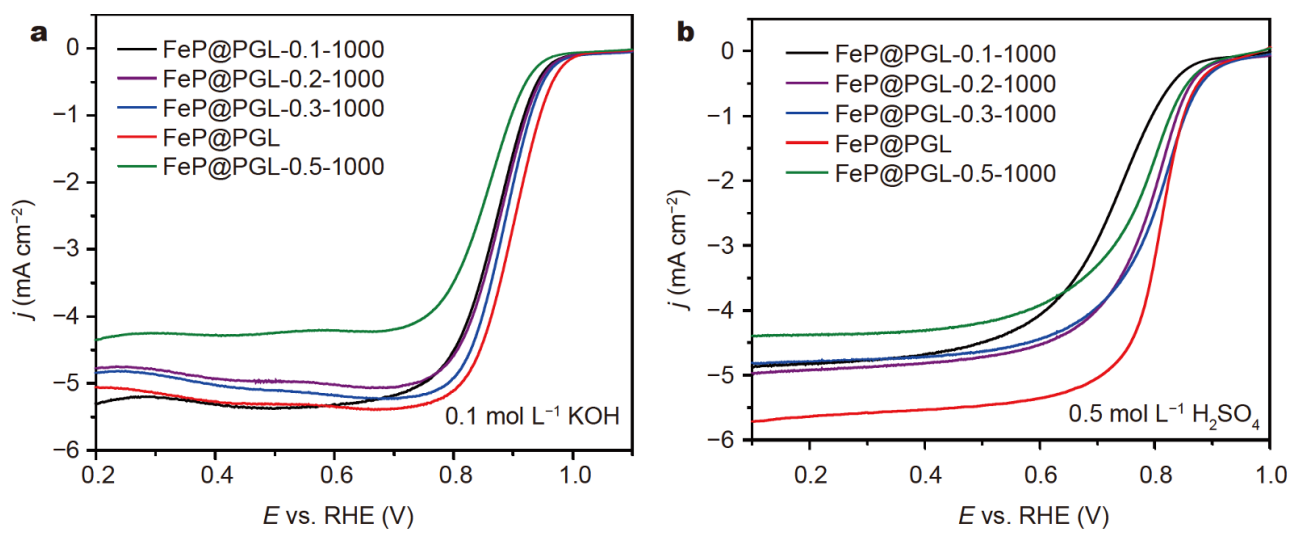

Figure 5 The LSV curves of FeP@PGL-X-1000 samples in $\mathrm{O}_{2}$-saturated (a) $0.1 \mathrm{~mol} \mathrm{~L}-1 \mathrm{KOH}$ solution, and (b) $0.5 \mathrm{~mol} \mathrm{~L}^{-1} \mathrm{H}_{2} \mathrm{SO}_{4}$ solution. 

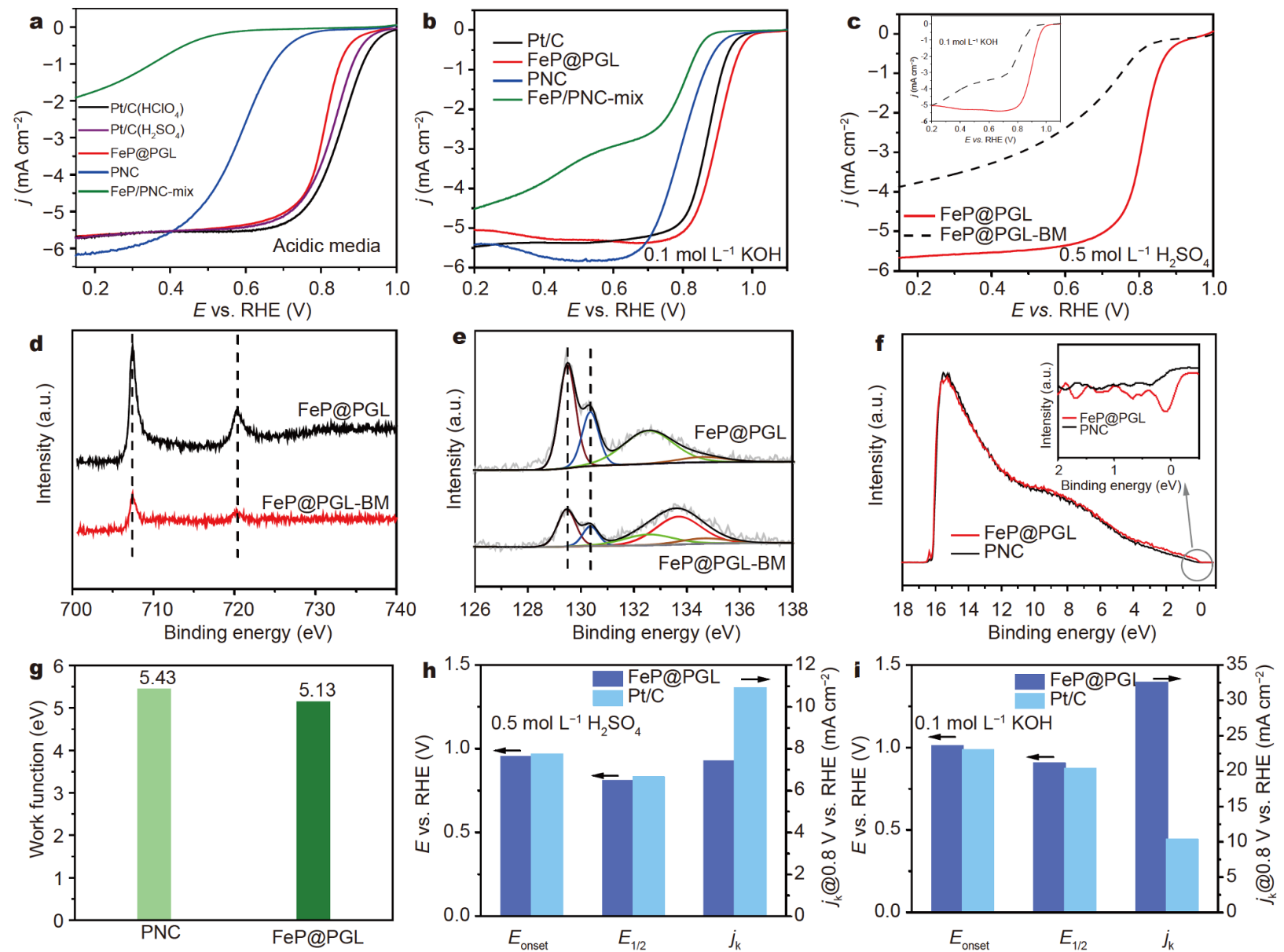

Figure 6 The LSV curves of the as-prepared catalysts and $\mathrm{Pt} / \mathrm{C}$ in $\mathrm{O}_{2}$-saturated (a) $0.5 \mathrm{~mol} \mathrm{~L}^{-1} \mathrm{H}_{2} \mathrm{SO}_{4}$ solution, $0.1 \mathrm{~mol} \mathrm{~L}^{-1} \mathrm{HClO}_{4}$ solution and (b) $0.1 \mathrm{~mol} \mathrm{~L}{ }^{-1} \mathrm{KOH}$ solution. (c) The LSV curves of FeP@PGL and FeP@PGL-BM in $\mathrm{O}_{2}$-saturated $0.5 \mathrm{~mol} \mathrm{~L}^{-1} \mathrm{H}_{2} \mathrm{SO}_{4}$ solution, and (inset) 0.1 mol L KOH solution. (d) The Fe 2p XPS spectra of FeP@PGL and FeP@PGL-BM. (e) The P 2p XPS spectra of FeP@PGL and FeP@PGL-BM. (f) The UPS survey of samples, and (inset) the differential of Fermi edge region. (g) The derived work functions of samples. The $E_{\text {onset }}, E_{1 / 2}$ and $j_{\mathrm{k}}$ of FeP@PGL and $\mathrm{Pt} / \mathrm{C}$ in $\mathrm{O}_{2}$-saturated (h) $0.5 \mathrm{~mol} \mathrm{~L}^{-1} \mathrm{H}_{2} \mathrm{SO}_{4}$ solution, and (i) $0.1 \mathrm{~mol} \mathrm{~L}^{-1} \mathrm{KOH}$ solution.

$\left(E_{\text {onset }}\right)$ and half-wave $\left(E_{1 / 2}\right)$ potentials are up to 0.95 and $0.81 \mathrm{~V}$, respectively, still slightly lower than those values of $\mathrm{Pt} / \mathrm{C}$ tested in $0.5 \mathrm{~mol} \mathrm{~L}^{-1} \mathrm{H}_{2} \mathrm{SO}_{4}\left(E_{\text {onset }}: 0.96 \mathrm{~V}\right.$ and $\left.E_{1 / 2}: 0.83 \mathrm{~V}\right)$ and $0.1 \mathrm{~mol} \mathrm{~L}^{-1} \mathrm{HClO}_{4}\left(E_{\text {onset }}: 0.99 \mathrm{~V}\right.$ and $E_{1 / 2}: 0.85 \mathrm{~V}$ ), respectively (Fig. $6 \mathrm{~h}$ ). The diffusion limiting current density $\left(j_{\mathrm{L}}\right)$ and the kinetics limiting current density $\left(j_{\mathrm{k}}\right)$ at $0.8 \mathrm{~V}$ for FeP@PGL $\left(5.7,7.4 \mathrm{~mA} \mathrm{~cm}^{-2}\right.$ ) were similar with those of $\mathrm{Pt} / \mathrm{C}\left(5.7,10.9 \mathrm{~mA} \mathrm{~cm}^{-2}\right)$. These results indicate that FeP@PGL is one of the most effective Fe-based electrocatalysts for ORR in acidic media, compared with recently reported $\mathrm{Fe} / \mathrm{N} / \mathrm{C}$ catalysts as listed in Table S3. Without encapsulated FeP NPs, the sample PNC is far less efficient than FeP@PGL. In alkaline media (Fig. 6b), FeP@PGL exhibits rather high $E_{\text {onset }}$ $(1.01 \mathrm{~V})$ and $E_{1 / 2}(0.90 \mathrm{~V})$ potentials which are more positive than those of $\mathrm{Pt} / \mathrm{C}\left(E_{\text {onset }}: 0.99 \mathrm{~V}\right.$ and $E_{1 / 2}$ :
$0.87 \mathrm{~V}$ ), and among the best reported phosphide/carbon catalysts as listed in Table S4. Specifically, $j_{\mathrm{k}}$ at $0.85 \mathrm{~V}$ for FeP@PGL (32.5 mA cm${ }^{-2}$ ) is 3.1 times higher than that of $\mathrm{Pt} / \mathrm{C}\left(10.3 \mathrm{~mA} \mathrm{~cm}^{-2}\right)$. Similarly, PNC is also less efficient than FeP@PGL in alkaline media. It should be noted that in the catalyst FeP@PGL, though carbon-coated FeP NPs did not directly contact with the reactants, they had positive effects on the active sites of P-doped graphene layers and dramatically promoted the ORR activity via electron transfer. Moreover, the activity of FeP/PNC-mix is even far inferior than that of PNC, further proving the vital role of in-situ formed phosphorus-doped carbon layers wrapping around the FeP NPs.

In order to further confirm the positive effects of the encapsulated FeP NPs, FeP@PGL was treated by ballmilling to smash the coating carbon layers, and then the 
ball-milled sample was leached in hot acid solution to remove FeP NPs as the protection coating carbon was destroyed (the leached sample denoted as FeP@PGL$\mathrm{BM})$. In the XRD pattern of FeP@PGL-BM, the peak intensity of $\mathrm{FeP}$ was obviously reduced (Fig. S13). It was also observed that a large portion of FeP NPs were leached out as shown in the TEM image, leaving some residual empty carbon cages (Fig. S14). Meanwhile, the ORR activity of FeP@PGL-BM was greatly depressed in both acidic and alkaline media as shown in Fig. 6c. These results confirmed that the encapsulated FeP NPs indeed played a vital role in enhancing the active sites on the coating P-doped graphene layers where $\mathrm{O}_{2}$ was adsorbed and reduced. The XPS spectrum of FeP@PGL-BM was measured for comparison with FeP@PGL. In the Fe 2p spectrum shown in Fig. 6d, two peaks at 707.4 and $720.3 \mathrm{eV}$ from the residual encapsulated FeP NPs are well consistent with those of FeP@PGL, but the intensity is greatly reduced due to the leaching of some FeP NPs. There is no Fe signals of the surface oxidized FeP, indicating that the residual FeP NPs were still encapsulated in coating carbon layers. In the P 2p spectrum (Fig. 6e), P signals from the residual encapsulated FeP NPs are well consistent with those of FeP@PGL, while the signal of the broad peak is shifted to higher binding energy compared with that of FeP@PGL. By deconvoluting the broad peak, there is still a remaining (but intensity-reduced) peak at $132.6 \mathrm{eV}$ due to the residual P-doped carbon layers still coated on the FeP NPs, and a strong peak at about $133.6 \mathrm{eV}$ could be assigned to $\mathrm{P}-\mathrm{C}$ bonding, although this peak is in the similar position of $\mathrm{P}-\mathrm{O}$ bonding for bare $\mathrm{FeP}$. If the $133.6 \mathrm{eV}$ signal were ascribed to the $\mathrm{P}-\mathrm{O}$ bonding, there should have been corresponding oxidized FeP peaks in Fig. 6d, similar with the oxidized FeP signal shown in Fe spectrum of bare FeP (Fig. 4c), but actually this is not the case. Thus the signal at about $133.6 \mathrm{eV}$ could be assigned to $\mathrm{P}-\mathrm{C}$ in the empty P-doped carbon layers, because when the inner FeP NPs were removed, the electron transfer from the FeP to the carbon layer was subsequently eliminated, and so the binding energy of the phosphorous in P-doped graphene layers increased. Because $\mathrm{SCN}^{-}$anion has a high affinity to $\mathrm{Fe}$ and could poison $\mathrm{Fe}-\mathrm{N}_{x}$ sites, to identify whether iron-containing species are actives sites, a $\mathrm{SCN}^{-}$poison experiment was conducted. As shown in Fig. S15, the $E_{\text {onset }}$ and $E_{1 / 2}$ of FeP@PGL were almost unchanged after adding $0.01 \mathrm{~mol} \mathrm{~L}^{-1} \mathrm{KSCN}$ into $0.1 \mathrm{~mol} \mathrm{~L}^{-1} \mathrm{KOH}$ solution, confirming the active sites were not based on iron-containing species. The above results provide clear evidence that in FeP@PGL there is electron transfer from the encapsulated
FeP NPs to P-doped graphene layers, thus enhancing the ORR performance.

As UPS is effective to analyze the valence band electrons and the local work function [46], here UPS spectra were measured to calculate the surface work function of FeP@PGL. The spectra and the calculated work functions of samples are shown in Fig. 6f, g. The local work function of FeP@PGL is $5.13 \mathrm{eV}, 0.3 \mathrm{eV}$ lower than that of PNC, indicating that the encapsulated FeP NPs modified the electron state of the coating carbon surface. As reported in literature, theoretical calculation demonstrates that the work function decreases by $0.1-0.5 \mathrm{eV}$ with different numbers of carbon layers coating on Fe particles, leading to improved ORR performance [20]. As one of the several factors that would influence the ORR property, a lower surface work function would be helpful to overcome energy barrier to extract electron from the catalyst surface, and thus would improve the ORR activity [47-49].

To explore the ORR kinetics of FeP@PGL, LSV curves at various rotation rates in $\mathrm{O}_{2}$-saturated $0.5 \mathrm{~mol} \mathrm{~L}^{-1}$ $\mathrm{H}_{2} \mathrm{SO}_{4}$ and $0.1 \mathrm{~mol} \mathrm{~L}^{-1} \mathrm{KOH}$ solutions are shown in Fig. $7 \mathrm{a}, \mathrm{d}$, and the $j_{\mathrm{L}}$ increases with higher rotation rate. The corresponding Koutecky-Levich (K-L) plots at different electrode potentials exhibit linearity (insets), suggesting first-order reaction kinetics of ORR on FeP@PGL [50]. As calculated by K-L equation, the electron transfer numbers $(n)$ are $\sim 3.7$ and 4.0 in acidic and alkaline media, respectively. In addition, the RDE test was carried out to check the $\mathrm{H}_{2} \mathrm{O}_{2}$ yield and the electron transfer number. From 0.3 to $0.8 \mathrm{~V}$, the yield of $\mathrm{H}_{2} \mathrm{O}_{2}$ was below $10 \%$ and the electron transfer numbers of FeP@PGL were about 3.8 in both acidic and alkaline media (Fig. 7b, e), indicating that the ORR on FeP@PGL underwent an efficient four-electron process. The Tafel curves derived from the polarization curves are shown in Fig. $7 \mathrm{c}$, f, FeP@PGL displayed a Tafel slop of $73 \mathrm{mV} \mathrm{dec}^{-1}$ in acidic media, almost similar with that of $\mathrm{Pt} / \mathrm{C}\left(60 \mathrm{mV} \mathrm{dec}{ }^{-1}\right)$. A lower Tafel slop of FeP@PGL than that of Pt/C in alkaline media (64 vs. $67 \mathrm{mV} \mathrm{dec}^{-1}$ ) indicated that FeP@PGL exhibited a faster kinetics in alkaline media [51-53].

Stability is another important parameter of catalysts, particularly in acidic solution. During a chronoamperometric response test, the relative current density of FeP@PGL remained 90\% after 30,000 s in acidic media, while the value for $\mathrm{Pt} / \mathrm{C}$ remained only $81 \%$ (Fig. 8a). FeP@PGL also exhibited excellent cycling stability in acidic media, and the $E_{1 / 2}$ shifted only $-20 \mathrm{mV}$ after 5000 continuous cycles (Fig. 8b). In alkaline media, FeP@PGL displayed superior long-term stability and cycling stability 

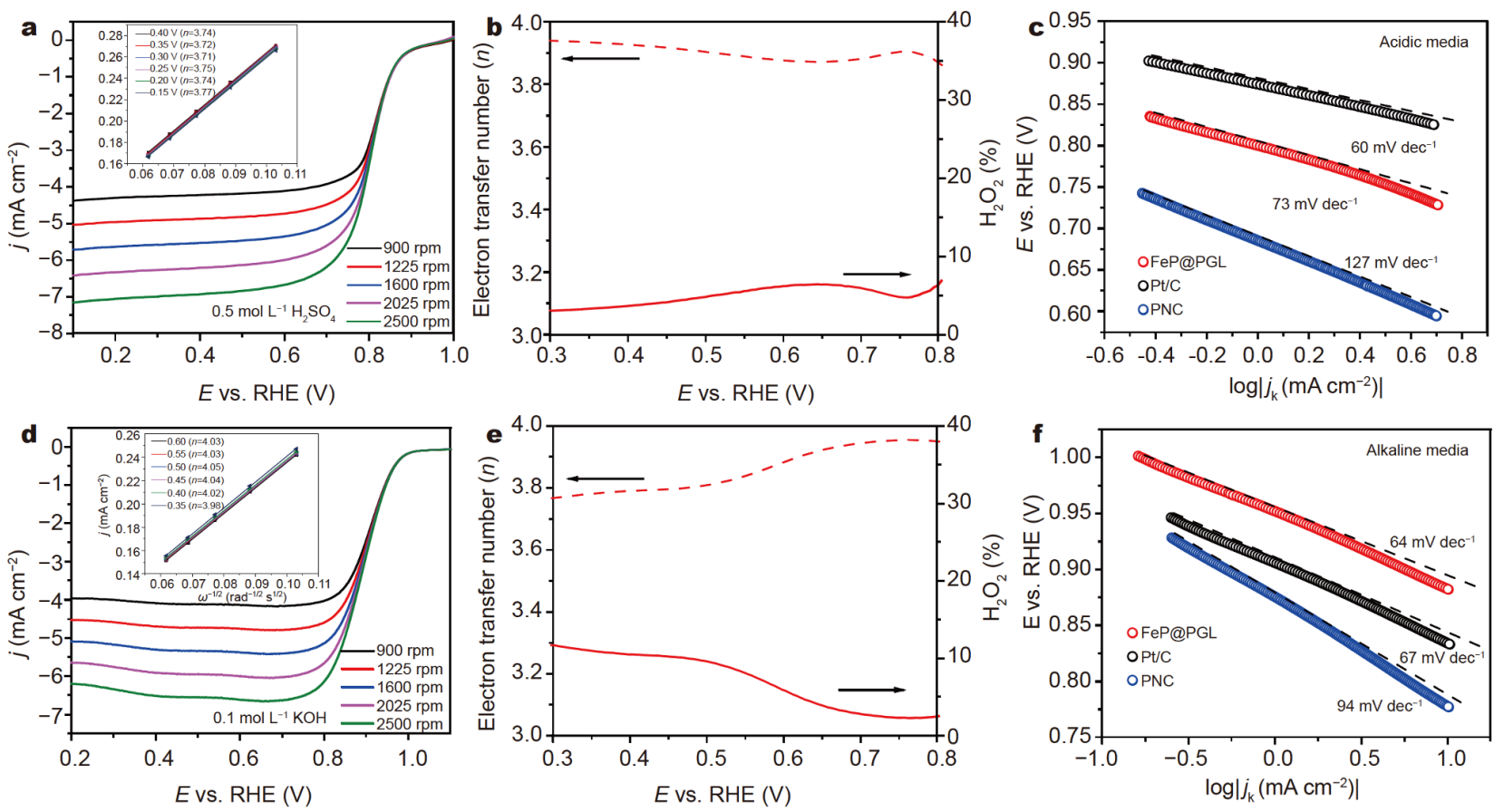

Figure 7 The LSV curves of FeP@PGL on RDE at different rotation rates in $\mathrm{O}_{2}$-saturated (a) $0.5 \mathrm{~mol} \mathrm{~L}^{-1} \mathrm{H}_{2} \mathrm{SO}_{4}$ solution and (d) 0.1 mol L ${ }^{-1} \mathrm{KOH}$ solution, with the corresponding K-L plots and electron transfer numbers at different potentials (insets). $\mathrm{H}_{2} \mathrm{O}_{2}$ yield and electron transfer numbers of FeN/SNC-900-3 obtained from RRDE measurements in (b) $0.5 \mathrm{~mol} \mathrm{~L}^{-1} \mathrm{H}_{2} \mathrm{SO}_{4}$ solution and (e) $0.1 \mathrm{~mol} \mathrm{~L}^{-1} \mathrm{KOH}$ solution. The Tafel plots obtained from the RDE measurements for FeP@PGL, PNC and Pt/C at $1600 \mathrm{rpm}$ in $\mathrm{O}_{2}$-saturated (c) $0.5 \mathrm{~mol} \mathrm{~L}^{-1} \mathrm{H}_{2} \mathrm{SO}_{4}$ solution and (f) $0.1 \mathrm{~mol} \mathrm{~L}{ }^{-1} \mathrm{KOH}$ solution.
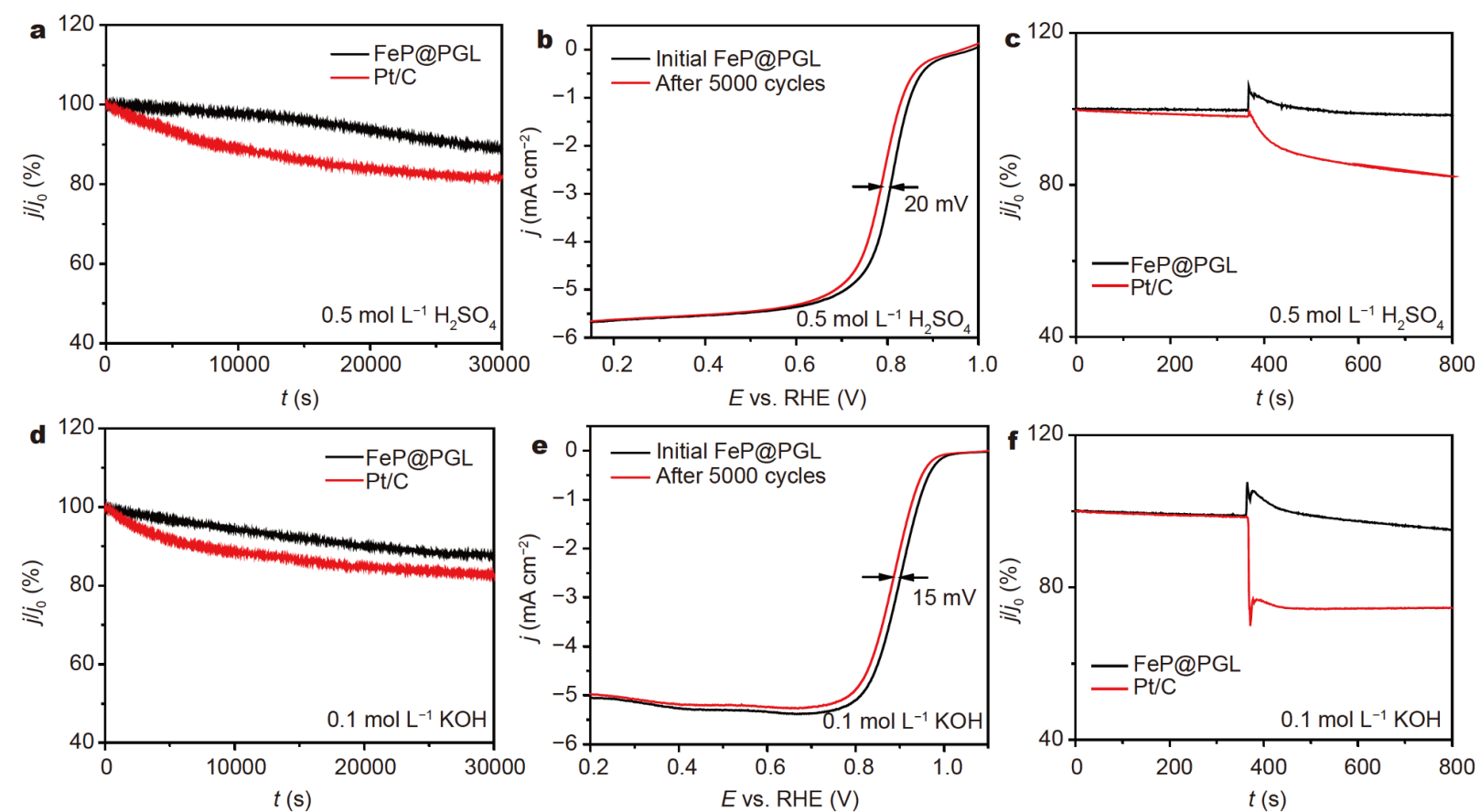

Figure 8 The chronoamperometric responses of FeP@PGL and Pt/C in $\mathrm{O}_{2}$-saturated (a) $0.5 \mathrm{~mol} \mathrm{~L}^{-1} \mathrm{H}_{2} \mathrm{SO}_{4}$ solution and (d) $0.1 \mathrm{~mol} \mathrm{~L} \mathrm{KOH}^{-1}$ solution. The LSV curves of FeP@PGL before and after 5000 cycles in $\mathrm{O}_{2}$-saturated (b) $0.5 \mathrm{~mol} \mathrm{~L}^{-1} \mathrm{H}_{2} \mathrm{SO}_{4}$ solution and (e) $0.1 \mathrm{~mol} \mathrm{~L} \mathrm{~L}^{-1} \mathrm{KOH}$ solution. The chronoamperometric responses of FeP@PGL and Pt/C with the addition of methanol in $\mathrm{O}_{2}$-saturated (c) $0.5 \mathrm{~mol} \mathrm{~L}^{-1} \mathrm{H}_{2} \mathrm{SO}_{4}$ solution and (f) $0.1 \mathrm{~mol} \mathrm{~L}^{-1} \mathrm{KOH}$ solution. 
shown in Fig. 8d, e, with only $-15 \mathrm{mV}$ shift of $E_{1 / 2}$ after 5000 continuous cycles. Combined with the above characterization results, it could be deduced that the superior stability is attributed to the protection of carbon layers. TEM images (Fig. S16) of FeP@PGL after the long-term stability test show the original morphologies and structure with carbon-layer-coated FeP NPs. Fe $2 p$ and P 2p XPS spectra (Fig. S17) of FeP@PGL after the long-term stability test are consistent with that of the original FeP@PGL (Fig. 4b, c), except for the relatively low signal due to the small amount of the sample obtained from the electrode. Though TEM and XPS results demonstrate the relatively stable structure of FeP@PGL during the longterm test, some structural change at the atomic level, such as carbon corrosion during the ORR, would be difficult to identify by TEM and XPS methods. The slight decay of activity might be due to the carbon corrosion after longtime contact with electrolytes and reactants. Moreover, the tolerance against methanol was evaluated (Fig. 8c, f). When methanol was injected into the electrolytes, FeP@PGL exhibited no current decay while the current density of $\mathrm{Pt} / \mathrm{C}$ suffered a sharp decrease. From the above,
FeP@PGL possessed excellent stability and tolerance against methanol in both acidic and alkaline media.

FeP@PGL was further integrated into a primary Zn-air battery as the cathode catalyst to explore its application potential in energy devices (illustrated in Fig. 9a), and the open-circuit potential of the $\mathrm{Zn}$-air battery was up to $1.48 \mathrm{~V}$ (Fig. 9b). In the polarization and power density curves (Fig. 9c), the peak discharge power density of the Zn-air battery based on FeP@PGL was $180 \mathrm{~mW} \mathrm{~cm}^{-2}$, higher than that based on $\mathrm{Pt} / \mathrm{C}\left(140 \mathrm{~mW} \mathrm{~cm}^{-2}\right)$. The discharge stability was further investigated, and the battery with FeP@PGL exhibited a stable performance in the long-time galvanostatic discharge test under currents of 5 and $10 \mathrm{~mA} \mathrm{~cm}^{-2}$ without noticeable voltage variation, indicating the excellent stability of FeP@PGL in the Znair battery (as shown in Fig. 9d). The superior Zn-air battery performance is attributed to the efficient ORR activity and stability of FeP@PGL.

\section{CONCLUSION}

Nanocomposite catalyst FeP@PGL was fabricated by a direct pyrolysis method. The catalyst was composed of
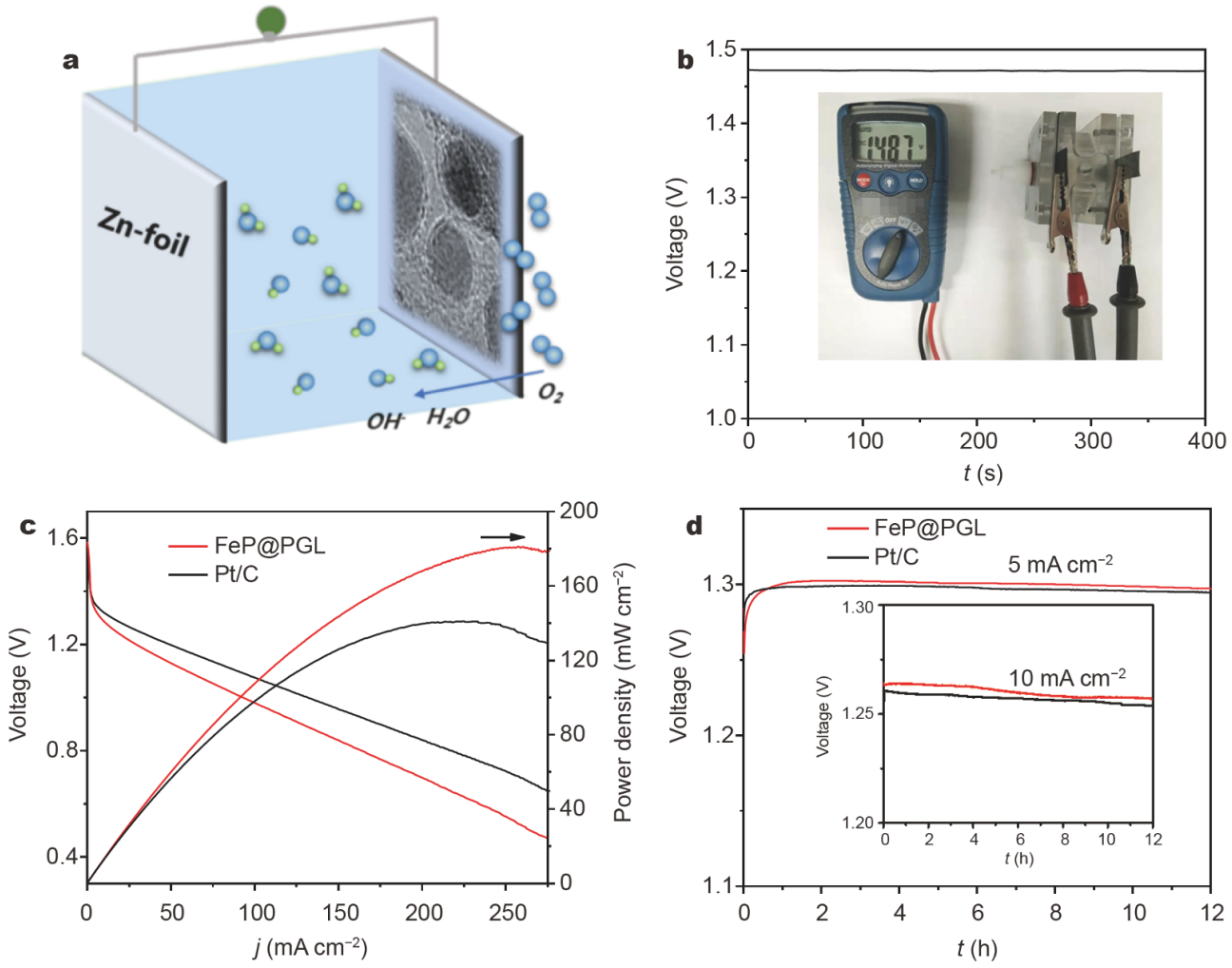

Figure 9 (a) Schematic of the primary Zn-air battery. (b) Open-circuit potential of the FeP@PGL assembled Zn-air battery; inset is the photograph of the primary Zn-air battery, showing an open-circuit potential of $1.487 \mathrm{~V}$. (c) The polarization curves and the corresponding power densities. (d) Discharge curves of FeP@PGL and Pt/C assembled $\mathrm{Zn}$-air batteries at 5 and $10 \mathrm{~mA} \mathrm{~cm}{ }^{-2}$ current densities. 
nitrogen-doped carbon nanosheets with embedded FeP NPs, which were encapsulated by in-situ formed phosphorus-doped graphene layers. The interfacial charge transfer between the encapsulated FeP NPs and the Pdoped graphene layers was identified, and the local work function of the catalyst surface was also reduced by the interfacial interaction. The interfacial charge behavior between the encapsulated $\mathrm{FeP}$ and phosphorus-doped graphene layers played a vital role in enhancing the ORR performance. The FeP@PGL catalyst exhibited excellent ORR performances, with positive onset and half-wave potentials, up to 1.01 and $0.90 \mathrm{~V} v s$. RHE in alkaline media (superior than $\mathrm{Pt} / \mathrm{C}$ ), and 0.95 and $0.81 \mathrm{~V} v$ s. RHE in acidic media (almost similar with $\mathrm{Pt} / \mathrm{C}$ ), respectively. Meanwhile, the carbon layers protected $\mathrm{FeP}$ from being oxidized and dissolved, resulting in excellent stability. Our research provides a facile synthetic method for catalysts with excellent ORR activity and stability, and gives an insight into the mechanism of $\mathrm{FeP} /$ carbon encapsulation catalysts for ORR. Nevertheless, to further improve the ORR performance, especially in acidic media, it is still a challenge to control the size of FeP NPs as well as the composition of the coating carbon layers during the procedure of high-temperature pryolysis.

Received 30 July 2020; accepted 18 September 2020; published online 16 December 2020

1 Chen Z, Higgins D, Yu A, et al. A review on non-precious metal electrocatalysts for PEM fuel cells. Energy Environ Sci, 2011, 4: 3167-3192

2 Jaouen F, Proietti E, Lefèvre M, et al. Recent advances in nonprecious metal catalysis for oxygen-reduction reaction in polymer electrolyte fuelcells. Energy Environ Sci, 2011, 4: 114-130

3 Nie Y, Li L, Wei Z. Recent advancements in Pt and Pt-free catalysts for oxygen reduction reaction. Chem Soc Rev, 2015, 44: 2168-2201

4 Shao M, Chang Q, Dodelet JP, et al. Recent advances in electrocatalysts for oxygen reduction reaction. Chem Rev, 2016, 116: 3594-3657

5 Spendelow JS, Papageorgopoulos DC. Progress in PEMFC MEA component R\&D at the DOE fuel cell technologies program. Fuel Cells, 2011, 11: 775-786

6 Wu G, Zelenay P. Nanostructured nonprecious metal catalysts for oxygen reduction reaction. Acc Chem Res, 2013, 46: 1878-1889

7 Dai L, Xue Y, Qu L, et al. Metal-free catalysts for oxygen reduction reaction. Chem Rev, 2015, 115: 4823-4892

8 Hang C, Zhang J, Zhu J, et al. In situ exfoliating and generating active sites on graphene nanosheets strongly coupled with carbon fiber toward self-standing bifunctional cathode for rechargeable Zn-air batteries. Adv Energy Mater, 2018, 8: 1703539

9 Zhang J, Sun Y, Zhu J, et al. Defect and pyridinic nitrogen engineering of carbon-based metal-free nanomaterial toward oxygen reduction. Nano Energy, 2018, 52: 307-314

10 Gewirth AA, Varnell JA, DiAscro AM. Nonprecious metal catalysts for oxygen reduction in heterogeneous aqueous systems. Chem
Rev, 2018, 118: 2313-2339

11 Wang W, Jia Q, Mukerjee S, et al. Recent insights into the oxygenreduction electrocatalysis of $\mathrm{Fe} / \mathrm{N} / \mathrm{C}$ materials. ACS Catal, 2019, 9: 10126-10141

12 Cheng $\mathrm{Y}, \mathrm{He} \mathrm{S}, \mathrm{Lu} \mathrm{S}$, et al. Iron single atoms on graphene as nonprecious metal catalysts for high-temperature polymer electrolyte membrane fuel cells. Adv Sci, 2019, 6: 1802066

13 Ye W, Chen S, Lin Y, et al. Precisely tuning the number of Fe atoms in clusters on $\mathrm{N}$-doped carbon toward acidic oxygen reduction reaction. Chem, 2019, 5: 2865-2878

$14 \mathrm{Ni} \mathrm{B}, \mathrm{Wu} \mathrm{L}$, Chen R, et al. Fe/Co-based nanoparticles encapsulated in heteroatom-doped carbon electrocatalysts for oxygen reduction reaction. Sci China Mater, 2019, 62: 1626-1641

15 Tan H, Li Y, Kim J, et al. Sub-50 nm iron-nitrogen-doped hollow carbon sphere-encapsulated iron carbide nanoparticles as efficient oxygen reduction catalysts. Adv Sci, 2018, 5: 1800120

16 Jiang WJ, Gu L, Li L, et al. Understanding the high activity of Fe$\mathrm{N}-\mathrm{C}$ electrocatalysts in oxygen reduction: $\mathrm{Fe} / \mathrm{Fe}_{3} \mathrm{C}$ nanoparticles boost the activity of $\mathrm{Fe}-\mathrm{N}_{x}$. J Am Chem Soc, 2016, 138: 3570-3578

17 Hu Y, Jensen JO, Zhang W, et al. Hollow spheres of iron carbide nanoparticles encased in graphitic layers as oxygen reduction catalysts. Angew Chem Int Ed, 2014, 53: 3675-3679

$18 \mathrm{Wu} \mathrm{ZY,} \mathrm{Xu} \mathrm{XX,} \mathrm{Hu} \mathrm{BC,} \mathrm{et} \mathrm{al.} \mathrm{Iron} \mathrm{carbide} \mathrm{nanoparticles} \mathrm{en-}$ capsulated in mesoporous $\mathrm{Fe}-\mathrm{N}$-doped carbon nanofibers for efficient electrocatalysis. Angew Chem Int Ed, 2015, 54: 8179-8183

19 Li Z, Wei L, Jiang WJ, et al. Chemical state of surrounding iron species affects the activity of $\mathrm{Fe}-\mathrm{N}_{x}$ for electrocatalytic oxygen reduction. Appl Catal B-Environ, 2019, 251: 240-246

20 Deng D, Yu L, Chen X, et al. Iron encapsulated within pod-like carbon nanotubes for oxygen reduction reaction. Angew Chem Int Ed, 2013, 52: 371-375

21 Liu X, Liu H, Chen $\mathrm{C}$, et al. $\mathrm{Fe}_{2} \mathrm{~N}$ nanoparticles boosting $\mathrm{FeN}_{x}$ moieties for highly efficient oxygen reduction reaction in Fe-N-C porous catalyst. Nano Res, 2019, 12: 1651-1657

22 Zhang J, He D, Su H, et al. Porous polyaniline-derived $\mathrm{FeN}_{x} \mathrm{C} / \mathrm{C}$ catalysts with high activity and stability towards oxygen reduction reaction using ferric chloride both as an oxidant and iron source. J Mater Chem A, 2014, 2: 1242-1246

$23 \mathrm{Xu} \mathrm{X}$, Shi C, Chen R, et al. Iron phosphide nanocrystals decorated in situ on heteroatom-doped mesoporous carbon nanosheets used for an efficient oxygen reduction reaction in both alkaline and acidic media. RSC Adv, 2017, 7: 22263-22269

24 Zhang R, Zhang C, Chen W. FeP embedded in N, P dual-doped porous carbon nanosheets: an efficient and durable bifunctional catalyst for oxygen reduction and evolution reactions. J Mater Chem A, 2016, 4: 18723-18729

$25 \mathrm{Hu} \mathrm{K}$, Xiao Z, Cheng Y, et al. Iron phosphide/N, P-doped carbon nanosheets as highly efficient electrocatalysts for oxygen reduction reaction over the whole $\mathrm{pH}$ range. Electrochim Acta, 2017, 254: 280-286

26 Fan X, Kong F, Kong A, et al. Covalent porphyrin frameworkderived $\mathrm{Fe}_{2} \mathrm{P} @ \mathrm{Fe}_{4} \mathrm{~N}$-coupled nanoparticles embedded in $\mathrm{N}$-doped carbons as efficient trifunctional electrocatalysts. ACS Appl Mater Interfaces, 2017, 9: 32840-32850

27 Long $\mathrm{C}$, $\mathrm{Li} \mathrm{X}$, Guo J, et al. Electrochemical reduction of $\mathrm{CO}_{2}$ over heterogeneous catalysts in aqueous solution: recent progress and perspectives. Small Methods, 2018, 3: 1800369

28 Yang F, Abadia M, Chen C, et al. Design of active and stable oxygen reduction reaction catalysts by embedding $\mathrm{Co}_{x} \mathrm{O}_{y}$ nanoparticles into nitrogen-doped carbon. Nano Res, 2016, 10: 97-107 
29 Wang Z, Li B, Ge X, et al. $\mathrm{Co}_{0} \mathrm{Co}_{3} \mathrm{O}_{4} @ P P D$ core@bishell nanoparticle-based composite as an efficient electrocatalyst for oxygen reduction reaction. Small, 2016, 12: 2580-2587

30 Mahmood J, Li F, Kim C, et al. Fe@ $\mathrm{C}_{2} \mathrm{~N}$ : A highly-efficient indirect-contact oxygen reduction catalyst. Nano Energy, 2018, 44: 304-310

31 Zhang X, Lin J, Chen S, et al. Co nanoparticles encapsulated in $\mathrm{N}$ doped carbon nanosheets: enhancing oxygen reduction catalysis without metal-nitrogen bonding. ACS Appl Mater Interfaces, 2017, 9: 38499-38506

32 Pandiyan R, Oulad Elhmaidi Z, Sekkat Z, et al. Reconstructing the energy band electronic structure of pulsed laser deposited CZTS thin films intended for solar cell absorber applications. Appl Surf Sci, 2017, 396: 1562-1570

33 Yuan H, Hou Y, Wen Z, et al. Porous carbon nanosheets codoped with nitrogen and sulfur for oxygen reduction reaction in microbial fuel cells. ACS Appl Mater Interfaces, 2015, 7: 18672-18678

34 Wei W, Liang $\mathrm{H}$, Parvez $\mathrm{K}$, et al. Nitrogen-doped carbon nanosheets with size-defined mesopores as highly efficient metal-free catalyst for the oxygen reduction reaction. Angew Chem Int Ed, 2014, 53: 1570-1574

35 Liang HW, Zhuang X, Brüller S, et al. Hierarchically porous carbons with optimized nitrogen doping as highly active electrocatalysts for oxygen reduction. Nat Commun, 2014, 5: 4973

36 Wang X, Ma W, Xu Z, et al. Metal phosphide catalysts anchored on metal-caged graphitic carbon towards efficient and durable hydrogen evolution electrocatalysis. Nano Energy, 2018, 48: 500-509

37 Yang DS, Bhattacharjya D, Inamdar S, et al. Phosphorus-doped ordered mesoporous carbons with different lengths as efficient metal-free electrocatalysts for oxygen reduction reaction in alkaline media. J Am Chem Soc, 2012, 134: 16127-16130

38 Yu Y, Peng Z, Asif M, et al. FeP nanocrystals embedded in $\mathrm{N}$ doped carbon nanosheets for efficient electrocatalytic hydrogen generation over a broad $\mathrm{pH}$ range. ACS Sustain Chem Eng, 2018, 6: $11587-11594$

39 Li R, Wei Z, Gou X. Nitrogen and phosphorus dual-doped graphene/carbon nanosheets as bifunctional electrocatalysts for oxygen reduction and evolution. ACS Catal, 2015, 5: 4133-4142

40 Ahn SH, Yu X, Manthiram A. "Wiring" Fe- $\mathrm{N}_{x}$-embedded porous carbon framework onto 1D nanotubes for efficient oxygen reduction reaction in alkaline and acidic media. Adv Mater, 2017, 29: 1606534

41 Huang Z, Pan $\mathrm{H}$, Yang W, et al. In situ self-template synthesis of Fe-N-doped double-shelled hollow carbon microspheres for oxygen reduction reaction. ACS Nano, 2018, 12: 208-216

42 Kong A, Zhu X, Han Z, et al. Ordered hierarchically micro- and mesoporous $\mathrm{Fe}-\mathrm{N}_{x}$-embedded graphitic architectures as efficient electrocatalysts for oxygen reduction reaction. ACS Catal, 2014, 4: 1793-1800

43 Jiang P, Liu Q, Liang Y, et al. A cost-effective 3D hydrogen evolution cathode with high catalytic activity: $\mathrm{FeP}$ nanowire array as the active phase. Angew Chem Int Ed, 2014, 53: 12855-12859

44 Zhang Z, Lu B, Hao J, et al. FeP nanoparticles grown on graphene sheets as highly active non-precious-metal electrocatalysts for hydrogen evolution reaction. Chem Commun, 2014, 50: 11554-11557

45 Zheng Y, Cheng P, Xu J, et al. MOF-derived nitrogen-doped nanoporous carbon for electroreduction of $\mathrm{CO}_{2}$ to $\mathrm{CO}$ : the calcining temperature effect and the mechanism. Nanoscale, 2019, 11: 49114917

46 Yang HB, Miao J, Hung SF, et al. Identification of catalytic sites for oxygen reduction and oxygen evolution in $\mathrm{N}$-doped graphene materials: Development of highly efficient metal-free bifunctional electrocatalyst. Sci Adv, 2016, 2: e1501122

47 Lyu Y, Wang R, Tao L, et al. In-situ evolution of active layers on commercial stainless steel for stable water splitting. Appl Catal BEnviron, 2019, 248: 277-285

48 Li X, Liu W, Zhang M, et al. Strong metal-phosphide interactions in core-shell geometry for enhanced electrocatalysis. Nano Lett, 2017, 17: 2057-2063

49 Lee DH, Lee WJ, Lee WJ, et al. Theory, synthesis, and oxygen reduction catalysis of Fe-porphyrin-like carbon nanotube. Phys Rev Lett, 2011, 106: 175502

50 Liang $\mathrm{Y}, \mathrm{Li} \mathrm{Y}$, Wang $\mathrm{H}$, et al. $\mathrm{Co}_{3} \mathrm{O}_{4}$ nanocrystals on graphene as a synergistic catalyst for oxygen reduction reaction. Nat Mater, 2011, 10: $780-786$

51 Zhao Y, Wan J, Yao H, et al. Few-layer graphdiyne doped with sphybridized nitrogen atoms at acetylenic sites for oxygen reduction electrocatalysis. Nat Chem, 2018, 10: 924-931

52 Han J, An P, Liu S, et al. Reordering d orbital energies of single-site catalysts for $\mathrm{CO}_{2}$ electroreduction. Angew Chem Int Ed, 2019, 58: $12711-12716$

53 Long C, Wang K, Shi Y, et al. Tuning the electronic structure of $\mathrm{PtRu}$ bimetallic nanoparticles for promoting the hydrogen oxidation reaction in alkaline media. Inorg Chem Front, 2019, 6: 29002905

Acknowledgements This work was supported by the National Natural Science Foundation of China (21773128, 21534005, and 21421001).

Author contributions $\mathrm{Ni} \mathrm{B}$, Chen R and Wu L conducted the experiments. All authors contributed to experimental design, data analysis and interpretation. $\mathrm{Ni} \mathrm{B}$ and Chen $\mathrm{T}$ wrote the manuscript.

Conflict of interest The authors declare no competing financial interests.

Supplementary information Experimental details and supporting data are available in the online version of the paper.

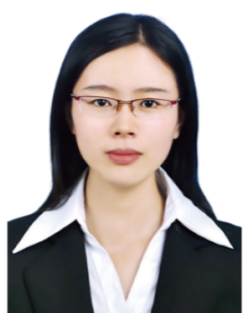

Baoxia Ni received her $\mathrm{PhD}$ degree from Nankai University in 2020. Her research focuses on the design and synthesis of nanostructured carbon electrocatalysts.

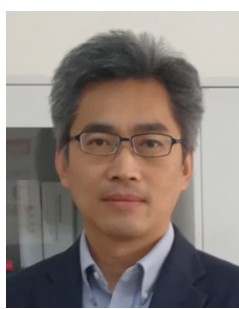

Tiehong Chen received his $\mathrm{BSc}$ and $\mathrm{PhD}$ degrees from Nankai University in 1990 and 1996, respectively. He joined Nankai University in 1996. $\mathrm{He}$ is currently a professor at the School of Materials Science and Engineering. His current research interests include the syntheses of zeolites and mesoporous materials, heterogeneous catalysis and electrocatalysis. 


\section{磷氮掺杂石墨烯层封装 $\mathrm{FeP}$ 纳米颗粒的增强 ORR 催化性能}

倪保霞 ${ }^{1}$, 陈攴 $^{1}$, 武鲁明 $^{1}$, 孙平川 ${ }^{2}$, 陈铁红 ${ }^{*}$

摘要 开发高效的非贵金属氧还原反应 $(\mathrm{ORR})$ 催化剂来替代铂基 催化剂受到了广泛关注. 设计合成在碱性电解质和酸性电解质中 均表现出高催化活性的非贵金属催化剂仍然是一个挑战. 在本文 中, 我们通过前驱体热解法制备了一种纳米复合催化剂 ( $\mathrm{FeP} @ \mathrm{PGL})$, 该催化剂由氮掺杂的碳纳米片以及镶嵌在片层上的 磷掺杂石墨烯层封装磷化铁 $(\mathrm{FeP})$ 纳米颗粒组成. FeP@PGL催化剂 表现出优异的ORR催化性能, 在碱性介质中的起始电位和半波电 势分别高达 $1.01 \mathrm{~V}$ 和 $0.90 \mathrm{~V} v s$. RHE; 在酸性介质中的起始电位和 半波电势分别高达 $0.95 \mathrm{~V}$ 和 $0.81 \mathrm{~V} v$ s. RHE. 通过详细的电子显微和 谱学表征, 我们发现碳纳米片基质与包裹纳米颗粒的碳包裹层存 在组成的差别, 磷掺杂主要发生在包裹 $\mathrm{FeP}$ 纳米颗粒的石墨烯层上. 封装的 $\mathrm{FeP}$ 纳米颗粒与外层磷掺杂石墨烯层之间存在界面电荷转 移, 并且通过界面相互作用降低了催化剂表面的功函数. FeP和磷 掺杂石墨烯层之间的界面协同作用对于增强催化剂ORR活性至关 重要. 本文不仅证明了封装型 $\mathrm{FeP}$ 基纳米复合催化剂在氧还原反应 上的应用价值, 而且为界面电荷转移效应及其在ORR过程中的作 用提供了实验证据. 